\title{
Severity Scoring System for Ventricular Septal Defect
}

\author{
Nirmal Gupta
}

Published online: 30 January 2009

(C) Springer Science+Business Media, LLC 2009

To the Editor:

I read with interest the article entitled "Severity Scoring System for Ventricular Septal Defect" by El Oakley et al. [1] on a subject, which at some time or other every pediatric cardiac surgeon encounters in his or her career. First, I wish to contend one of the authors' comments regarding their reported incidence of residual ventricular septal defect (RVSD) recurrence. This incidence seems too high and therefore requires examination by the treating team. Having said this, in India, like in most other developing countries, patients ranging an entire age spectrum undergo repair of RVSD; therefore, the most important factor in residual shunting across an RVSD is not its size, which was elucidated as one of first four criteria. The patient's pulmonary vascular resistance and reactivity at the time of this reparative surgery, as well as after the procedure, becomes an important determinant. I also believe that the three other criteria (i.e., the Qp:Qs ratio is subdivided into three categories $[<1.5,1.5$ to $<2$, and $\geq 2.0]$; the right and left ventricular pressure ratio is subdivided into three categories $[<0.5,0.5$ to $<0.75$, and $\geq 0.75]$; and heart failure symptoms are subdivided into NYHA classes II/III and IV as well as pulmonary oedema requiring assisted ventilation-discussed and pondered by the authors are somehow linked or, perhaps more suitable to say, interdependent of each other. Therefore, I stress a simple point: If residual shunting is $>1.5$ to 2 or $\geq 2$, it indicates that pulmonary vascular resistance is still low. In such cases of residual RVSD, the treating surgeon must consider an important criterion, i.e., the patient's symptoms. Finally, even a small possibility of developing endocarditis may outweigh everything, especially in the patient with a prosthetic patch in-situ that warrants closure. In this scenario, the importance of all criteria fades unless the risk of future endocarditis is explained and accepted by the parents and/or the patient. I must also add a point in favour of catheter-based interventions, which may be of great help in many of these patients if it is available and affordable, especially in the context of patients in developing countries (catheter-based intervention has not been possible at my institution because it cannot be borne by many patients' financial situations).

\section{Reference}

1. El Oakley R, Al Qethamy H, Al Saeedi A, Al Yousef S, Momenah TS, Al Faraidi Y (2008) Pediatr Cardiol 29:1016-1017

N. Gupta $(\bowtie)$

Sanjay Gandhi Postgraduate Institute of Medical Sciences,

Lucknow, UP 226104, India

e-mail: nirmal@sgpgi.ac.in 